\title{
Globe
}

Revue internationale d'études québécoises

\section{Denise Lemieux (éd.) : Traité de la culture. Sainte-Foy, Éditions de l’IQRC et les Presses de l’Université Laval, 2002}

\section{Carmen Mata Barreiro}

Volume 7, numéro 2, 2004

URI : https://id.erudit.org/iderudit/1000869ar

DOI : https://doi.org/10.7202/1000869ar

Aller au sommaire du numéro

Éditeur(s)

Globe, Revue internationale d'études québécoises

ISSN

1481-5869 (imprimé)

1923-8231 (numérique)

Découvrir la revue

Citer ce compte rendu

Barreiro, C. M. (2004). Compte rendu de [Denise Lemieux (éd.) : Traité de la

culture. Sainte-Foy, Éditions de l'IQRC et les Presses de l'Université Laval, 2002].

Globe, 7(2), 203-208. https://doi.org/10.7202/1000869ar d'utilisation que vous pouvez consulter en ligne.

https://apropos.erudit.org/fr/usagers/politique-dutilisation/ 


\section{Denise Lemieux (éd.)}

Traité de la culture.

\section{Sainte-Foy, Éditions de l'IQRC et les Presses de l'Université Laval, 2002.}

Il est assez exceptionnel de commencer une recension en qualifiant un ouvrage d' "incontournable". Le Traité de la culture, dirigé par Denise Lemieux, mérite en effet cette épithète. Ce livre de 1089 pages constitue l'aboutissement d'un projet né à l'INRS-Culture et Société et terminé à l'INRS Urbanisation, Culture et Société, centre né de la fusion de l'IQRC (Institut québécois de recherche sur la culture) et de l'INRS (Institut national de la recherche scientifique). Denise Lemieux, dans l'introduction le présente comme un travail d'équipe auquel ont collaboré plusieurs chercheurs de ce centre ainsi que des chercheurs appartenant à d'autres institutions et en particulier aux diverses universités québécoises.

Soixante-quatre auteurs, spécialistes de différents domaines concernant la culture, ont été invités à participer à une profonde réflexion sur la culture au Québec. L'objectif initial était de rassembler des bilans portant sur la recherche réalisée à l'intérieur de diverses disciplines au cours des 25 dernières années. Chaque chercheur devait élaborer la synthèse des recherches dans son domaine spécifique, retracer les grandes étapes de l'évolution et s'efforcer de rendre les connaissances accessibles au plus grand nombre. Tout ce travail d'analyse et de synthèse a permis de mettre en lumière la grande richesse de la création au Québec de même que le dynamisme et la rigueur de la recherche sur la culture. La convergence de différentes approches et de diverses disciplines permet de rendre visibles la diversité et la richesse des problématiques abordées et des thèmes, l'évolution des disciplines consolidées et l'émergence de nouvelles spécialités. On peut aussi constater l'importance des interactions entre les domaines de la création, de la politique et de l'économie comme éléments moteurs de la recherche et générateurs de ses priorités.

L'ouvrage est structuré en six parties. La première partie s'intitule "Histoire et mémoire: conservation, savoirs, représentation. Dans "L'histoire du Québec: tendances récentes et enjeux ", Joanne Burgess souligne la transformation d'une historiographie qui, ayant été marquée par la prépondérance de l'économique et du social pendant les années 
1970, évolue à partir de 1985 vers une multiplication des sujets, un "éclatement "où l'on constate l'influence d'autres disciplines et la genèse de champs interdisciplinaires tels que les études urbaines et les études féministes; l'auteure met particulièrement l'accent sur "l'explosion de l'histoire culturelle ". Dans "La tradition orale et les savoirs artisanaux ", Bernard Genest analyse l'évolution et les apports des études folkloriques et de l'ethnologie. Dans "Le Patrimoine ", Paul-Louis Martin rappelle la façon dont le secteur du patrimoine s'est professionnalisé, décrit les différents champs développés (patrimoine architectural, patrimoine industriel, patrimoine mobilier) et souligne la prise de conscience, par la société, de la place du patrimoine comme espace de mémoire. Le domaine de la muséologie est quant à lui étudié par Raymond Montpetit, dans "Musées et muséologie. Un champ de recherche dynamique en émergence ".

La deuxième partie traite des " Milieux et diversité culturelle». Des spécialistes de diverses disciplines se penchent sur les différents espaces et sur les acteurs sociaux qui font partie de la société - et de la culture québécoise, laquelle a éprouvé des transformations profondes tout au long du $\mathrm{xx}^{\mathrm{e}}$ siècle. Carole Lévesque parcourt " l'anthropologie amérindianiste québécoise " à partir de la décennie 1960 ; elle montre comment son évolution tient non seulement à des intérêts disciplinaires mais aussi à des préoccupations sociétales. Fernand Harvey approfondit "La région culturelle et la culture en région ": il considère que "le palier régional s'avère [...] un espace intermédiaire non seulement utile, mais nécessaire pour cerner le phénomène culturel au Québec • (p. 135), et expose un bilan de la culture régionale. Myriam Simard élabore un bilan critique du rapport entre "Espace rural et culture". Jack Jedwab analyse le milieu culturel de la communauté anglophone dans "La 'Révolution tranquille' des Anglo-Québécois ", tandis que Denise Lemieux explore les études sur "Les femmes et la création culturelle".

Trois articles abordent l'univers des immigrants : Sylvie Taschereau examine l'évolution de la recherche sur les "Migrations et relations ethniques ", dans le cadre de l'histoire. Gilles Bibeau traite de la question de l'altérité dans "Accueillir "l'autre" dans la distinction. Essai sur le Québec pluriel " où il retrace l'évolution des politiques d'immigration mises en œuvre par le Québec depuis 1975 et les propositions des chercheurs en vue de construire une société québécoise pluraliste. Enfin, Annick Germain situe le pluralisme culturel à l'intérieur de la ville dans "La 
culture urbaine au pluriel ? Métropole et ethnicité ", où elle dresse un panorama de la période qui s'étend de "l'émergence du cosmopolitisme montréalais - à celle du * Montréal multiethnique contemporain .

La troisième partie, " Économie, travail et culture ", est consacrée à la dimension économique et à la professionnalisation du champ artistique. Gaëtan Tremblay et Jean-Guy Lacroix traitent de " La marchandisation et l'industrialisation de la culture, de l'information et de la communication *. Claude Martin étudie la genèse de l'analyse économique de la production culturelle au Québec et au Canada dans "Culture et économie . François Colbert analyse "Le marketing et la gestion des arts"sous l'angle de la recherche scientifique. Et Guy Bellavance et Benoit Laplante étudient l'évolution de la " Professionnalisation et socialisation du champ artistique : la formation professionnelle des artistes au $x^{e}$ siècle .

Une quatrième partie, la plus étendue, est consacrée à " La production culturelle - où la littérature, l'édition et le livre, les arts visuels, l'architecture et le design, la musique, les arts de la scène et les industries culturelles sont abordés. Le premier aspect étudié dans le domaine de la littérature est "L'institution littéraire": Lucie Robert y analyse le long processus qui va de la constitution des lettres dans la période de la Nouvelle-France à l'utopie laïque de la littérature québécoise et à la situation actuelle où la fragmentation du champ littéraire déterminerait la remise en question des assises institutionnelles de la littérature nationale (p. 358). Laurent Mailhot fait une revue historique et critique des recherches concernant "La réception littéraire " et s'attarde sur une série d'auteurs "privilégiés par la critique ". Maurice Lemire étudie la spécificité de "La carrière d'écrivain au Québec", et Robert Dion se penche sur "La critique littéraire "savante au Québec.

Toujours dans le domaine de la production littéraire, Lianne Moyes aborde "La littérature anglophone du Québec", "un champ d'étude relativement nouveau (p. 423). Simon Harel analyse le travail critique concernant "La littérature issue des communautés culturelles " et apporte sa réflexion au débat sur la dynamique entre cette littérature et la littérature québécoise. Denis Saint-Jacques et Marie-José Des Rivières étudient " La littérature populaire * à partir du $x^{e} x^{e}$ siècle, sa littérarité et son rôle social. 


\section{REVUE INTERNATIONALE D'ÉTUDES QUÉBÉCOISES}

La réflexion consacrée à "L'édition et le livre " est ouverte par l'analyse de l'histoire de l'édition littéraire au Québec par Jacques Michon. Suzanne Pouliot étudie les travaux consacrés à "L'édition [littéraire] québécoise pour l'enfance et la jeunesse • en évoquant parallèlement la recherche faite en Europe francophone. Les études sur "Les manuels scolaires * sont analysées par Paul Aubin dans une approche où convergent les recherches sur l'histoire de l'imprimé et celles sur l'histoire de l'éducation. L'analyse de l'histoire des "librairies et [d]es bibliothèques publiques " au Québec et de la façon dont la politique et la recherche les abordent est menée par Jean-Paul Baillargeon.

L'exploration de l'univers des arts visuels est introduite par un portrait historique du champ de l'art au Québec dressé par Marcel Fournier et Véronique Rodriguez dans "Le monde des arts visuels au Québec ". François-Marc Gagnon étudie la recherche tant en art ancien qu'en art moderne et contemporain du Québec dans "Les beaux-arts ". La situation des "arts médiatiques au Québec " est présentée par Louise Poissant et Andrée Fortin s'intéresse à "L'art et la place publique .

La réflexion sur l'architecture et le design est inaugurée par l'analyse de Georges Adamczyk, "La profession d'architecte et les esthétiques contemporaines", traitant des débats qui ont lieu dans l'univers de l'architecture au Québec et des moteurs de la recherche architecturale. "Le domaine du design " est présenté comme " nouvel objet " par Gérald Baril et Michelle Comeau. Philippe Poullaouec-Gonidec aborde "Les cultures du paysage " comme un objet de réflexion, de préoccupation et d'intervention.

Dans la section du Traité consacrée à la musique, Marie-Thérèse Lefebvre considère "L'histoire de l'art musical " Jean Boivin s'intéresse à l'historiographie de la création musicale, Roger Chamberland étudie la chanson et la musique populaire québécoises et Nicole Beaudry tente une synthèse des travaux sur "Les pratiques musicales autochtones " du Québec.

Dans la section consacrée aux arts de la scène, Jean Cléo Godin analyse l'évolution de l'" institution théâtrale québécoise " pendant le dernier quart de siècle, "le virage de 1980 " et la "complexe recherche de son langage propre ". Gilbert David élabore un "Bilan critique des travaux en études théâtrales *. Iro Valaskakis Tembeck dresse un panorama critique 
de la danse québécoise et attire l'attention sur l'importance d'envisager une " culture chorégraphique élargie *. La réflexion qui clôt cette section touche "le cirque au Québec: une pratique culturelle méconnue ", un terrain très peu étudié dont Julie Boudreault présente l'évolution et l'état de la recherche.

La section portant sur les industries culturelles est d'abord consacrée à la radio: Michel Filion étudie l'évolution de la radio au Québec du point de vue juridique et politique, et Renée Legris se penche sur la littérature radiophonique. Dans le troisième article, William Straw expose la spécificité de "L'industrie du disque au Québec "et de la recherche qui y est consacrée. Dans le domaine du cinéma, Pierre Véronneau dresse l'état des recherches touchant aux "Institutions cinématographiques " alors qu'Esther Pelletier étudie l'émergence de l'attention pour le scénario et présente un bilan des études scénaristiques qui représentent, selon elle, un "champ mitoyen entre cinéma et littérature ". Dans le dernier volet, Jean Charron et Jean de Bonville analysent l'univers du journalisme et des journalistes, et Roger de La Garde élabore une analyse critique de la recherche sur la télévision au Québec.

La cinquième partie, intitulée "Consommateurs, amateurs et publics ", accueille la réflexion sur la société. Simon Langlois analyse comment une nouvelle culture matérielle est née au $x^{e}$ siècle avec l'émergence de "la société de consommation ". Gilles Pronovost offre un aperçu des " transformations des pratiques culturelles" au Québec par rapport aux comportements culturels dans d'autres pays. Léon Bernier et Guy Bellavance s'intéressent plus spécifiquement à la question du public.

La sixième et dernière partie intègre une réflexion sur les politiques culturelles. Diane Saint-Pierre fait une recension des études sur "les politiques culturelles en matière d'arts, de lettres et de communications " ainsi que sur les institutions. Michel de La Durantaye propose une approche des "Politiques culturelles municipales, locales et régionales, au Québec ", alors que Marie-Hélène Lavoie et Florian Sauvageau s'appuient sur une réflexion sur la mondialisation de la culture pour analyser la " concentration " des industries culturelles.

Ce survol du Traité de la culture nous permet d'apprécier la diversité des domaines culturels explorés ainsi que la volonté de rendre compte de la façon dont la recherche les a approchés au Québec. Tout en reflétant la richesse d'un univers d'investigation, cet ouvrage est lui-même 
représentatif de la spécificité de la recherche au Québec, de son dynamisme, de l'exigence de rigueur et de la volonté de renouveau qui y règnent.

La qualité des contenus et l'organisation de l'ensemble en font un excellent ouvrage de formation, un outil de recherche et un ouvrage de consultation. La qualité de l'index, de la table des matières et du répertoire thématique assure en effet une consultation rapide et efficace, et le foisonnement de bibliographies permet au chercheur d'approfondir davantage les différents secteurs de la culture.

Un ouvrage si ambitieux et si rigoureux pourrait envisager, dans de futures rééditions, d'ouvrir encore certains espaces de recherche sur la culture. Ainsi, une section pourrait être consacrée à la langue dans ses rapports à la culture et à la littérature au Québec (identité, traduction, culture), ou encore à la culture québécoise sous le regard étranger (projets de recherche internationaux, développement des études québécoises à l'étranger), ce qui contribuerait à rendre visibles le pouvoir de fascination de la culture québécoise et les apports de la recherche sur celle-ci.

Carmen Mata Barreiro Universidad Autónoma de Madrid (Espagne)

\section{Marie-Pier Luneau}

Lionel Groulx. Le mythe du berger.

Montréal, Leméac, 2003.

À la bourse des valeurs intellectuelles, les écrivains, intellectuels et phénomènes sociaux de la première moitié du vingtième siècle québécois sont en forte hausse. Depuis quelques années, en effet, des chercheurs de multiples disciplines concentrent leurs regards de ce côté, modifiant considérablement ce que l'on croyait savoir sur cette période. Des ouvrages aussi divers que ceux de Louise Bienvenue, Daniel Chartier, Alain G. Gagnon et Michel Sarra-Bournet, Hélène PelletierBaillargeon, Esther Trépanier et Jean-Philippe Warren, ont déplacé les repères historiques habituels et montré, entre autres choses, que bien des traits associés à la culture et à la société québécoises modernes ne 